\title{
Brief Communication: Detection of glacier surge activity using cloud computing of Sentinel-1 radar data
}

\author{
Paul Willem Leclercq ${ }^{1}$, Andreas Kääb ${ }^{1}$, and Bas Altena ${ }^{2}$ \\ ${ }^{1}$ Department of Geosciences, Oslo University, Oslo, Norway \\ ${ }^{2}$ IMAU, Utrecht University, Utrecht, the Netherlands
}

Correspondence: Paul Leclercq (paul.leclercq@geo.uio.no)

\begin{abstract}
For studying the flow of glaciers and their response to climate change it is important to detect glacier surges. Here, we compute within Google Earth Engine the normalized differences between winter maxima of Sentinel-1 C-band radar backscatter image stacks over subsequent years. We arrive at a global map of annual backscatter changes, which are for glaciers in most cases related to changed crevassing associated with surge-type activity. For our demonstration period 2018-2019 we detected 69 surging glaciers, with many of them not classified so far as surge type. Comparison with glacier surface velocities shows that we reliably find known surge activities. Our method can support operational monitoring of glacier surges, and some other special events such as large rock and snow avalanches.
\end{abstract}

\section{Introduction}

Glacier surges are an example of glacier flow instability where the ice velocities strongly increase over a short period of time, typically less than a decade (Meier and Post, 1969). Only a small fraction of the world's glaciers are of surge type (Jiskoot et al., 1998; Sevestre and Benn, 2015). Still, glacier surging is of special scientific and applied interest. Studying glacier surges increases understanding of glacier flow and its instability (e.g. Thøgersen et al., 2019). Glacier surges disturb the link with climate and thus climatic interpretation of changes in glacier size or mass balance (Zemp et al., 2020). Surges can also constitute potential natural hazards (Kääb et al., 2021; Truffer et al., 2021).

Glacier surges have been detected by a wide variety of methods, including in-situ observations of strong glacier advance or increase in surface velocity (e.g. Kamb et al., 1985). Several studies provide regional inventories of surge-type glaciers based on remote sensing images of morphological features of past or ongoing surge activity, such as strong glacier advance, looped moraines, crevasse patterns, and sheared-off glacier tributaries (e.g. Jiskoot et al., 2003; Grant et al., 2009; Mukherjee et al., 2017). Morphological evidence of surges provides a more complete overview of surge-type glaciers than directly observed surge activity alone. However, the connection between different types of morphological evidence and glacier surge activity is not always straightforward leading to uncertainty in the attribution of surge activity (Jiskoot et al., 2003; Sevestre and Benn, 2015). Surges can be more directly detected from measurements of glacier surface velocity using feature tracking in optical or radar satellite images (e.g. Quincey et al., 2011; Altena et al., 2019; Haga et al., 2020) and by measurement of surface elevation change (e.g. Sund et al., 2009; Gardelle et al., 2013). 
https://doi.org/10.5194/tc-2021-89

Preprint. Discussion started: 11 May 2021

(c) Author(s) 2021. CC BY 4.0 License.

\section{(c) (i)}

In the present study we explore the potential of comparing the backscatter brightness of satellite synthetic aperture radar (SAR) amplitude images over time in order to monitor glacier surging. The underlying aim behind our study is to find a comparably simple and robust method to detect surges at global scale and at an annual time interval.

\section{Method}

Our method is based on variations in the strength of radar backscatter over time. As a surge implies substantial increase in the flow velocity and velocity gradients of a glacier, the glacier surface typically gets more crevassed and radar backscatter is increased during an active surge. Likewise will the glacier surface get less crevassed and therefore backscatter decrease at the end of an active surge phase. Comparison of the radar backscatter strength between two time intervals therefore helps to detect the build-up or decay of glacier surges. Thereby, the weather- and daylight-independence of SAR data offers the opportunity for highly systematic surveys and flexible choice of the time intervals to compare. In this study, we demonstrate annual changes in surge activity, noting that also shorter or longer time intervals might be of interest for certain applications. We use radar amplitude imagery from the EU/ESA Copernicus Sentinel-1 C-band mission that provides data with a global coverage since launch in April 2014 (Torres et al., 2012).

To detect annual change in radar backscatter, we compare radar image stacks from two consecutive winter seasons, January to March for the northern hemisphere and June to August for the southern hemisphere. Winter radar imagery reduces complications by additional backscatter changes such as from surface melt and changing water content of the snow and firn (Winsvold et al., 2018). We create aggregated images of maximum backscatter value for each pixel location over the 3-months winter periods. Then we calculate the normalized difference between the two aggregated maximum images to search for change in backscatter and to eventually identify surge activity.

We implemented our method in Google Earth Engine (GEE), a cloud-based platform that provides easy access to high performance computation on global remote-sensing datasets (Gorelick et al., 2017). Our implementation is inspired by the detection of ship traffic lanes in radar image stacks as exemplified by different authors (Gascoin, 2019, and the sources cited therein). The results given in this study are based on calibrated and ortho-corrected Sentinel-1 Ground Range Detected (GRD) scenes in cross-polarized (VH or HV) Interferometric Wide Swath (IW) mode, and mainly the descending path of Sentinel-1 that are available in GEE. However, we also use data from ascending path where descending data has no coverage (see Suppl.

50 Mat. for more details). The normalized difference index (NDI) between the 2018 and 2019 stack maximum images is calculated as $\mathrm{NDI}_{\text {MaxGRD, 2018-2019 }}=\frac{\max G R D_{2019}-\max G R D_{2018}}{\max G R D_{2019}+\max G R D_{2018}}$ We use GEE to visually explore the glacierized regions of the world and look for features of increased or decreased radar backscatter that can indicate glacier surge activity.

An example of an aggregated backscatter stack maximum image from the central Pamirs is shown in Fig. 1a, and the 2018-2019 NDI image for the same area is shown in Fig. 1b. This NDI image can be noisy, especially on steep mountain faces. Nevertheless, one can clearly recognize some larger distinct bright and dark regions in the NDI image that correspond to exceptional changes in backscatter from glacier surfaces. We have also masked the NDI image with the GLIMS glacier outlines (GLIMS and NSIDC, 2015 (updated 2018)) included in GEE to help identify the glacierized areas, as shown in the 
https://doi.org/10.5194/tc-2021-89

Preprint. Discussion started: 11 May 2021

(c) Author(s) 2021. CC BY 4.0 License.

(c) (i)

example in Fig. 1c. In this image it is easy to identify the bright patch as a glacier with increased backscatter in winter 2019 with respect to winter 2018. In Fig. 1c, also two dark patches reflect two glaciers, or tributaries, with decreased backscatter. In all three cases the changes in backscatter cover a large part of the glacier tongue and we interpret these changes as an indicator of surge activity.

GEE also provides the possibility to include optical images in additional image layers. We display Sentinel-2 images from summer 2017 and summer 2019 to examine visual signs of surge activity that can support our conclusions drawn from the backscatter analysis. For that purpose we create an optical composite image from the selection of all available Sentinel-2 images during July and August (northern hemisphere; January and February for the southern hemisphere) that have less than $80 \%$ cloud cover. We then take the pixel-wise median of the selected images after applying the provided cloud cover threshold and plot a RGB colour image of bands B4, B3, and B2, respectively.

We also compare our detection of surge activity from changing backscatter with identification of surges from glacier surface velocity measurements in Svalbard and Alaska. For Svalbard, we derive glacier surface velocity from own unpublished standard offset tracking between Sentinel-1 data (for method see e.g. Strozzi et al., 2017). For Alaska, we use glacier surface velocity generated from repeat Landsat optical satellite images using auto-RIFT (Gardner et al., 2018) provided by the NASA MeaSUREs ITS_LIVE project (Gardner et al., 2020).

\section{Results}

\subsection{Detailed example}

As a detailed example we discuss results for Negribreen and Sonklarbreen on the east coast of Spitsbergen, Svalbard. Fig 2a shows a clear increase in radar backscatter between winter 2018 and winter 2019 for Negribreen, which started to surge in late summer 2016 and had surface velocities peak in the melt season of 2017 (Haga et al., 2020). After the 2017 peak in surface velocity, they find a gradual slowdown in which the crevassing of the glacier surface, though, further intensified during the years 2018 and 2019. Haga et al. (2020) explain this from flow velocity being still high after the peak, which in turn led to continued stretch in the glacier ice. This indicates we can observe increase in backscatter even after the surge velocity peak. Our method reflects surface roughness maxima, not necessarily ice velocity maxima during a surge. Close to the terminus of Negribreen, the backscatter has still increased over the period 2019-2020 (Fig. 2b), indicating that the terminus continued to advance. Upstream from the terminus, backscatter decreased indicating less crevassing in this area, while the backscatter increased further upstream. The 2019-2020 NDI image on Negribreen thus represents an example of a glacier both with increased and decreased backscatter related to surge activity. We divide the detected surge activity thus in three groups: increased backscatter, decreased backscatter, and both increased and decreased backscatter (See also Suppl. Mat. Table S1 and Fig. S2). In the upper right of Fig. 2a,b the development of a surge of Sonklarbreen is visible. In the 2018-2019 NDI image (Fig. 2a) a slight increase in backscatter is already visible as well as a small advance of the glacier terminus. The surge is far more clear in the NDI image from the following year, 2019-2020 (Fig. 2b), with a prominent increase in radar backscatter and a clear advance of the glacier terminus. 
https://doi.org/10.5194/tc-2021-89

Preprint. Discussion started: 11 May 2021

(c) Author(s) 2021. CC BY 4.0 License.

(c) (i)

\subsection{Global results 2018-2019}

In total we found 69 glaciers with surge activity in the period 2018-2019 from changes in the radar backscatter. Of these, 31 displayed an increase, 29 a decrease, and 9 a combination of both increase and decrease in Sentinel-1 radar backscatter. The glaciers are located in the first-order RGI regions (RGI Consortium, 2017) Alaska (18 glaciers), Canadian Arctic North (2), Canadian Arctic South (2), Greenland (5), Svalbard (14), Russian Arctic (2), Central Asia (13), South Asia (West) (10), South Asia (East) (1), and Southern Andes (2) (see Sup Mat Table S1 and Sup Mat Fig. S2). We have also found 18 cases of change in backscatter for which we are not certain whether it can be classified as surge activity, listed in Table S1. In these cases the change in backscatter could be due to other processes than changes in ice velocity (see Section 3 in the Suppl. Mat.), or the velocity change could be related to another process than surge activity, such as calving instabilities.

According to the surge classification from Sevestre and Benn (2015) included in the RGI, there are earlier observations of surge activity (surge class 3) for 16 of the 69 glaciers that we find to have surge activity in the year 2018-2019. A further 8 of these 69 glaciers are classified as either possible (class 1) or probable (class 2) to have surge activity. For 10 glaciers where we find surge activity, Sevestre and Benn (2015) found no evidence of surge (class 0), and 35 of the 69 glaciers are not yet assigned a surge classification (class 9).

\subsection{Comparison with velocity measurements}

In Svalbard, the annual differences between winter surface velocities indicate surge behaviour for all the glaciers for which we detected surge activity in the radar backscatter difference. In addition, measurements of glacier velocity do not indicate glacier surge activity other than the surges we find in the NDI images. Interestingly, for several cases of distinct backscatter changes, surge activity is not immediately obvious from the radar velocities or supporting optical images. Only close inspection of velocity differences over time and velocity changes from several years confirm then the backscatter-based detection of surge activity. Examples of such cases include early phases of surges or 'partial' surges (surges that do not propagate into large parts of a glacier) (Sund et al., 2009). In Alaska, 16 of the 18 detected surges are supported by measured changes in surface velocity. For the two glaciers where velocity measurements do no support surge activity, we probably misinterpreted changes in radar backscatter due to firn processes as an indication of surge activity. See the Suppl. Mat. Section 4 and Fig. S5-S11 for more details.

\section{Discussion}

Comparison of the surge activity we detect from the radar backscatter difference images with glacier surface velocity suggests that the method we propose for surge detection is reliable. For both Svalbard and Alaska the velocity measurements support most of the surge activity we detect with the backscatter difference images. For two cases in Alaska we find no evidence of a surge in the velocity measurements. Our backscatter-based method of surge detection may in parts be more sensitive than remotely sensed velocity changes or visual inspection of optical images for morphological indicators, such that partial surges 
https://doi.org/10.5194/tc-2021-89

Preprint. Discussion started: 11 May 2021

(c) Author(s) 2021. CC BY 4.0 License.

(c) (i)

or surge onsets are picked up in the NDI image that are not (yet) easily visible otherwise. The time of switch from increasing to decreasing backscatter strength is not necessarily equivalent to the maximum ice velocity (see above example of Negribreen).

There are many possible causes other than glacier surge activity for differences in the brightness of radar backscatter stack maxima in two consecutive years. There can be acquisition and processing effects related to particularly steep terrain, such as radar layover and foreshortening (See Suppl. Mat. Section 2). In addition, we find cases of differences due to natural changes other than glacier velocity changes, such as changing glacial lakes, landslides and snow avalanche activity, and changes in firn conditions in the accumulation area (see Sup. Mat. Section 3). There is not always a clear distinction between changes in glacier velocity due to surge activity and other glacier instabilities such as calving instabilities. On the one hand this means that the method we present here could be interesting for many purposes other than detecting glacier surges. On the other hand, it is possible that backscatter changes resulting from other processes are misinterpreted as surge activity, leading to uncertainty in the classification. Table $\mathrm{S} 1$ includes 18 such cases.

To avoid misinterpretation it is helpful to complement the information from the radar backscatter difference images with optical images. Sometimes, the aggregated maximum radar backscatter images themselves, i.e. before differencing them, provide useful information. The backscatter difference images over multiple annual intervals can be investigated to find if the entire surge cycle can be detected.

Sevestre and Benn (2015) provide currently the most extensive global compilation of glacier surge activity. Their database includes 2317 surge-type glaciers. We look at a very limited time span and only detect surges that induce changes in radar backscatter in the year 2018 to 2019. Nevertheless, almost two thirds of the surging glaciers we find are not identified by Sevestre and Benn (2015), as included in the RGI, being either not assigned a surging class or classified as having no indication of surge activity. As our method detects ongoing surges only, in contrast to methods that study evidence of past surges (e.g. Jiskoot et al., 2003), a systematic overview of surging glaciers requires constant monitoring over a long period of time. It could be explored whether some form of object-oriented classification or machine learning could be of help to reduce the workload from exploring the backscatter difference images.

\section{Conclusions}

We have shown that differencing aggregated Sentinel-1 radar backscatter images over subsequent years has great potential to detect glacier surges. Surge-induced changes in surface roughness lead to an easily discernible increase or decrease in radar backscatter that we use to identify ongoing surge activity. We compare the results from our method with surge detection from surface velocity measurements for Alaska and Svalbard. The two methods largely identify the same surge activity. Some differences in surge detection could be due to the higher sensitivity of our backscatter-based method that is able to detect partial surges or surge onsets before these are well visible in the surface velocity data. For some cases, we can have misinterpreted backscatter changes caused by processes other than surge activity. The method presented here has a wider application than just glacier surge detection and could be further adapted to study these other processes as well. For correct surge detection we recommend additional information from optical satellites, aggregated radar backscatter images, and the temporal evolution of 
https://doi.org/10.5194/tc-2021-89

Preprint. Discussion started: 11 May 2021

(c) Author(s) 2021. CC BY 4.0 License.

(c) (1)

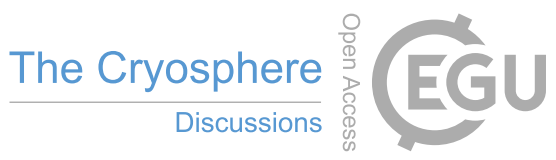

155 the normalized difference images. For our demonstration period 2018-2019 almost two-thirds of the 69 surging glaciers found are not yet assigned surge activity in the global data base. There could be far more surging glaciers than identified so far and the method presented here could contribute to their detection.

Code availability. The GEE code developed for this study will be made openly available before publication in TC.

Author contributions. AK conceived the study. PWL and AK performed the analysis, BA helped with the analysis of velocity measurements.

PWL prepared the manuscript with contributions from all authors.

Competing interests. The authors declare that they have no conflict of interest.

Acknowledgements. This study is partially financed by ESA through Glaciers_CCI and EarthExplorer 10 Harmony studies (4000109873/14/INB, 4000127593/19/I-NS, 4000127656/19/NL/FF/gp) and the Norwegian Copernicus Service/Norwegian Space Centre (NIT.06.15.5). The study is also a contribution to the Svalbard Integrated Arctic Earth Observing System SIOS. 
https://doi.org/10.5194/tc-2021-89

Preprint. Discussion started: 11 May 2021

(c) Author(s) 2021. CC BY 4.0 License.

(c) (i)

165

\section{References}

Altena, B., Scambos, T., Fahnestock, M., and Kääb, A.: Extracting recent short-term glacier velocity evolution over southern Alaska and the Yukon from a large collection of Landsat data, The Cryosphere, 13, 795-814, https://doi.org/10.5194/tc-13-795-2019, 2019.

Gardelle, J., Berthier, E., Arnaud, Y., and Kääb, A.: Region-wide glacier mass balances over the Pamir-Karakoram-Himalaya during 1999-2011, The Cryosphere, 7, 1263-1286, https://doi.org/10.5194/tc-7-1263-2013, 2013.

Gardner, A. S., Moholdt, G., Scambos, T., Fahnstock, M., Ligtenberg, S., van den Broeke, M., and Nilsson, J.: Increased West Antarctic and unchanged East Antarctic ice discharge over the last 7 years, The Cryosphere, 12, 521-547, https://doi.org/10.5194/tc-12-521-2018, https://tc.copernicus.org/articles/12/521/2018/, 2018.

Gardner, A. S., Fahnestock, M. A., and Scambos, T. A.: ITS LIVE Regional Glacier and Ice Sheet Surface Velocities, Data archived at National Snow and Ice Data Center, https://doi.org/10.5067/6II6VW8LLWJ7, 2020.

Gascoin, S.: Visualizing shipping lanes from Sentinel-1, website, https://labo.obs-mip.fr/multitemp/ visualizing-shipping-lanes-from-sentinel-1/, 2019.

GLIMS and NSIDC: Global Land Ice Measurements from Space glacier database, Compiled and made available by the international GLIMS community and the National Snow and Ice Data Center, Boulder CO, U.S.A., https://doi.org/10.7265/N5V98602, 2015 (updated 2018).

Gorelick, N., Hancher, M., Dixon, M., Ilyushchenko, S., Thau, D., and Moore, R.: Google Earth Engine: Planetary-scale geospatial analysis for everyone, Remote Sensing of Environment, 202, 18 - 27, https://doi.org/https://doi.org/10.1016/j.rse.2017.06.031, http: //www.sciencedirect.com/science/article/pii/S0034425717302900, big Remotely Sensed Data: tools, applications and experiences, 2017.

Grant, K. L., Stokes, C. R., and Evans, I. S.: Identification and characteristics of surge-type glaciers on Novaya Zemlya, Russian Arctic, Journal of Glaciology, 55, 960-972, https://doi.org/10.3189/002214309790794940, 2009.

Haga, O. N., McNabb, R., Nuth, C., Altena, B., Schellenberger, T., and Kääb, A.: From high friction zone to frontal collapse: dynamics of an ongoing tidewater glacier surge, Negribreen, Svalbard, Journal of Glaciology, pp. 742-754, https://doi.org/10.1017/jog.2020.43, 2020.

Jiskoot, H., Boyle, P., and Murray, T.: The incidence of glacier surging in Svalbard: evidence from multivariate statistics, Computers \& Geosciences, 24, 387-399, https://doi.org/10.1016/S0098-3004(98)00033-8, 1998.

Jiskoot, H., Murray, T., and Luckman, A.: Surge potential and drainage-basin characteristics in East Greenland, Annals of Glaciology, 36, 142-148, https://doi.org/10.3189/172756403781816220, 2003.

Kääb, A., Jacquemart, M., Gilbert, A., Leinss, S., Girod, L., Huggel, C., Falaschi, D., Ugalde, F., Petrakov, D., Chernomorets, S., Dokukin, M., Paul, F., Gascoin, S., Berthier, E., and Kargel, J.: Sudden large-volume detachments of low-angle mountain glaciers - more frequent than thought?, The Cryosphere, 15, 1751-1785, https://doi.org/10.5194/tc-15-1751-2021, 2021.

Kamb, B., Raymond, C. F., Harrison, W. D., Engelhardt, H., Echelmeyer, K. A., Humphrey, N., Brugman, M. M., and Pfeffer, T.: Glacier Surge Mechanism: 1982-1983 Surge of Variegated Glacier, Alaska, Science, 227, pp. 469-479, 1985.

Meier, M. F. and Post, A.: What are glacier surges?, Canadian Journal of Earth Sciences, 6, 807-817, https://pubs.geoscienceworld.org/cjes/ article-abstract/6/4/807/54772/What-are-glacier-surges, 1969.

Mukherjee, K., Bolch, T., Goerlich, F., Kutuzov, S., Osmonov, A., Pieczonka, T., and Shesterova, I.: Surge-Type Glaciers in the Tien Shan (Central Asia), Arctic, Antarctic, and Alpine Research, 49, 147-171, https://doi.org/10.1657/AAAR0016-021, 2017.

Quincey, D. J., Braun, M., Glasser, N. F., Bishop, M. P., Hewitt, K., and Luckman, A.: Karakoram glacier surge dynamics, Geophysical Research Letters, 38, n/a-n/a, https://doi.org/10.1029/2011GL049004, 2011. 
https://doi.org/10.5194/tc-2021-89

Preprint. Discussion started: 11 May 2021

(c) Author(s) 2021. CC BY 4.0 License.

(c) (1)

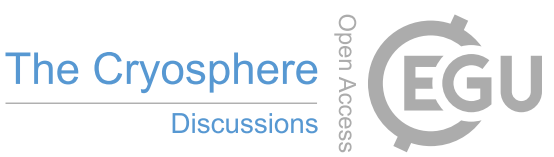

RGI Consortium: Randolph Glacier Inventory - A dataset of Global Glacier Outlines: Version 6.0, Technical Report, Global Land Ice Measurements from Space, Colorado, USA. Digital Media, https://doi.org/10.7265/N5-RGI-60, 2017.

Sevestre, H. and Benn, D. I.: Climatic and geometric controls on the global distribution of surge-type glaciers: implications for a unifying model of surging, Journal of Glaciology, 61, 646-662, https://doi.org/10.3189/2015JoG14J136, 2015.

205 Strozzi, T., Paul, F., Wiesmann, A., Schellenberger, T., and Kääb, A.: Circum-Arctic Changes in the Flow of Glaciers and Ice Caps from Satellite SAR Data between the 1990s and 2017, Remote Sensing, 9, 947, https://doi.org/10.3390/rs9090947, 2017.

Sund, M., Eiken, T., Hagen, J. O., and Kääb, A.: Svalbard surge dynamics derived from geometric changes, Annals of Glaciology, 50, 50-60, https://doi.org/10.3189/172756409789624265, 2009.

Thøgersen, K., Gilbert, A., Schuler, T. V., and Malthe-Sørenssen, A.: Rate-and-state friction explains glacier surge propagation, Nature

Communications, 10, https://doi.org/10.1038/s41467-019-10506-4, 2019.

Torres, R., Snoeij, P., Geudtner, D., Bibby, D., Davidson, M., Attema, E., Potin, P., Rommen, B., Floury, N., Brown, M., Traver, I. N., Deghaye, P., Duesmann, B., Rosich, B., Miranda, N., Bruno, C., L' Abbate, M., Croci, R., Pietropaolo, A., Huchler, M., and Rostan, F.: GMES Sentinel-1 mission, Remote Sensing of Environment, 120, 9-24, https://doi.org/10.1016/j.rse.2011.05.028, 2012.

Truffer, M., Kääb, A., Harrison, W., Osipova, G., Nosenko, G., Espizua, L., Gilbert, A., Fischer, L., Huggel, C., Craw Burns, P., and Lai, A.: Snow and Ice-Related Hazards, Risks, and Disasters (Second Edition), chap. 13 - Glacier surges, pp. 417-466, Elsevier, 2021.

Winsvold, S. H., Kääb, A., Nuth, C., Andreassen, L. M., van Pelt, W. J. J., and Schellenberger, T.: Using SAR satellite data time series for regional glacier mapping, The Cryosphere, 12, 867-890, https://doi.org/10.5194/tc-12-867-2018, 2018.

Zemp, M., Gärtner-Roer, I., Nussbaumer, S. U., Bannwart, J., Rastner, P., Paul, F., and Hoelzle, M., eds.: WGMS 2020. Global Glacier Change Bulletin No. 3 (2016-2017), ISC(WDS)/IUGG(IACS)/UNEP/UNESCO/WMO, World Glacier Monitoing Service, Zürich, Switzerland, 2020. 
https://doi.org/10.5194/tc-2021-89

Preprint. Discussion started: 11 May 2021

(c) Author(s) 2021. CC BY 4.0 License.

(c) (i)
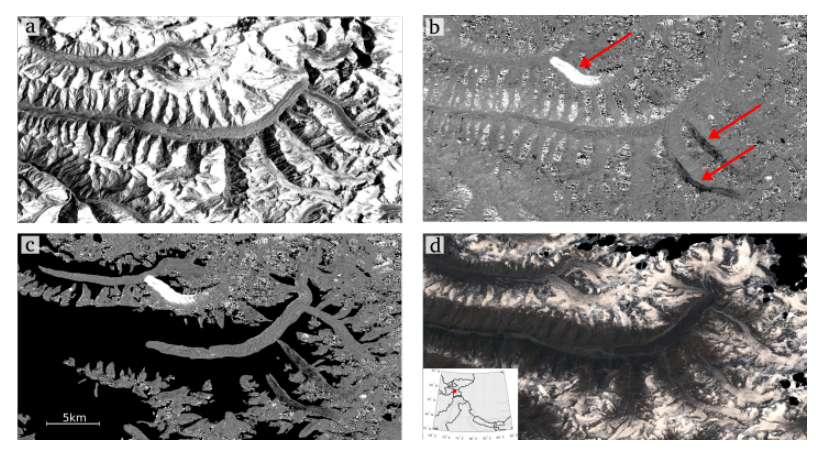

Figure 1. Example for detecting glacier surges from differencing backscatter stack maxima of different winter seasons for a glacierized area surrounding the Obihingo river basin in the central Pamirs, Tajikistan, a) Aggregated Copernicus Sentinel-1 maximum backscatter winter 2018. b) Normalized Difference Index (NDI) image from Sentinel-1 maximum brightness winter 2018 - winter 2019. Arrows indicate areas with increased and decreased radar backscatter over glaciers. c) NDI image 2018 - 2019 masked with GLIMS glacier outlines. d) Copernicus Sentinel-2 optical image summer 2019, with cloud mask in black; inset shows the location of the images. 
https://doi.org/10.5194/tc-2021-89

Preprint. Discussion started: 11 May 2021

(c) Author(s) 2021. CC BY 4.0 License.
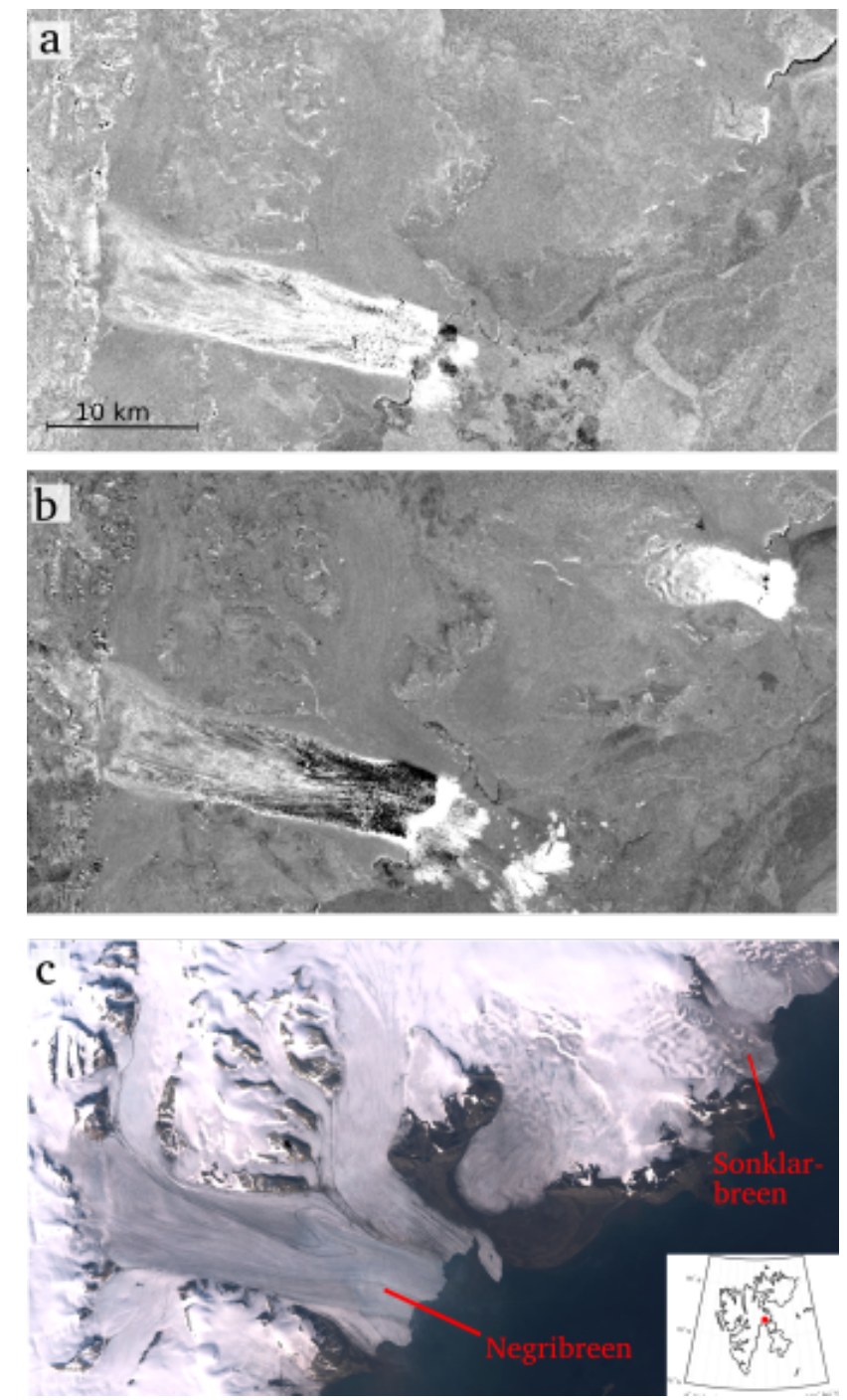

Figure 2. Copernicus Sentinel-1 NDI image of Negribreen and Sonklarbreen, Svalbard, for the periods a) 2018 - 2019, and b) 2019 - 2020 . c) Copernicus Sentinel-2 1st July - 31st Aug 2019 optical composite image, with a cloud mask in black. The inset shows the location in Svalbard of the glaciers shown in the images. 